\title{
GESTÃO ESTRATÉGICA E COMPARTILHAMENTO DA VISÃO EM MICRO E PEQUENAS EMPRESAS
}

\section{STRATEGIC MANAGEMENT AND SHARING THE VISION IN MICRO AND SMALL ENTERPRISES}

\section{GESTIÓN ESTRATÉGICA Y COMPARTIR LA VISION DE MICRO Y PEQUEÑAS EMPRESAS}

\section{Edmilson de Oliveira Lima PPGA/UNINOVE \\ E-mail: edmilsonlima@uninove.br (Brasil) \\ Louis Jacques Filion \\ Doutor em Management pela Lancaster University, Inglaterra \\ Professor do École des Hautes Études Commerciales de Montréal, Canadá \\ E-mail: louisjacques.filion@hec.ca (Canadá)}

Doutor em Administração pelo École des Hautes Études Commerciales de Montréal, Canadá Professor do Programa de Pós-Graduação em Administração da Universidade Nove de Julho -

\section{Oscar Dalfovo}

Doutor em Engenharia e Gestão do Conhecimento pela Universidade Federal de Santa Catarina UFSC

Professor da Fundação Universidade Regional de Blumenau - FURB

E-mail: dalfovo@furb.br (Brasil)

\section{Vladas Urbanavicius Junior}

Doutor em Administração pela Universidade Nove de Julho - UNINOVE

Professor da Faculdade de Ciências Sociais Aplicadas do Sul de Minas - FACESM

E-mail: vladasjunior@yahoo.com.br (Brasil) 


\title{
GESTÃO ESTRATÉGICA E COMPARTILHAMENTO DA VISÃO EM MICRO E PEQUENAS EMPRESAS ${ }^{1}$
}

\section{RESUMO}

Este artigo é um ensaio que trata de diferentes aspectos da gestão estratégica de micro e pequenas empresas (MPEs), os quais não são normalmente tratados na literatura, principalmente quanto aos processos de desenvolvimento e de compartilhamento da visão dos dirigentes dessas empresas com base na conversa estratégica. A abordagem utilizada é a da aprendizagem sistêmica, caracterizada pela utilização dos conceitos de visão e aprendizagem de modo descritivo e apoiado na vertente interpretativa da teoria de sistemas que é a metodologia de sistemas flexíveis. Antes, contudo, a necessidade desse tipo de abordagem é justificada, o potencial de contribuição dos conceitos de visão e aprendizagem é descrito e a abordagem em si é caracterizada com o uso da literatura. Os recursos explorados para a construção do trabalho são, principalmente, a literatura disponível, exemplos variados, argumentação e descrição. As contribuições geradas concernem uma perspectiva diferenciada para se compreender a gestão estratégica das MPEs, mais conhecimentos sobre aspectos pouco tratados em estudos precedentes, assim como temas e enfoques potencialmente úteis para a realização de novas pesquisas.

Palavras-chave: Aprendizagem; Compartilhamento; Conversa estratégica; Gestão estratégica; Visão.

\section{STRATEGIC MANAGEMENT AND SHARED VISION IN MICRO AND SMALL ENTERPRISES}

\begin{abstract}
This essay addresses aspects of strategic management in micro and small enterprises (MSEs) that are not usually treated in the literature, especially regarding the development and sharing processes of directors' vision based on strategic conversation. It follows a systemic learning approach, which is descriptive and based on soft systems methodology, an interpretive perspective of systems theory. Its central concepts are vision and learning. First, however, the essay justifies the need for this type of approach, describes the potential contribution of the vision and learning concepts, and characterizes the approach itself by exploring the literature. The resources employed to develop this article are primarily the available literature, various examples, argumentation, and description. The contributions that it generates include a differentiated perspective to understand strategic management of MSEs, more knowledge about certain aspects scarcely addressed in previous studies, and potentially useful themes and understandings for further studies.
\end{abstract}

Keywords: Learning; Sharing; Strategic management; Strategic conversation; Vision.

\footnotetext{
${ }^{1}$ Este artigo se baseia em grande parte em trabalhos anteriores aqui citados. Suas seções 5 e 6 retrabalham parte das contribuições desenvolvidas previamente por Filion e Lima (2011) e parcialmente já retomadas por Schmitt, Lima e Husson (2012).
} 
Edmilson de Oliveira Lima, Louis Jacques Filion, Oscar Dalfovo \& Vladas Urbanavicius Junior

\section{GESTIÓN ESTRATÉGICA Y VISIÓN COMPARTIDA \\ EN MICRO Y PEQUEÑAS EMPRESAS}

\section{RESUMEN}

El artículo es un ensayo que trata sobre diferentes aspectos de la gestión estratégica de las micro y pequeñas empresas (MYPE) que no suelen ser tratados en la literatura, sobre todo en relación con los procesos de desarrollo y compartir de la visión de los líderes de estas empresas basados en la conversación estratégica. El enfoque utilizado es del aprendizaje sistémico, caracterizado por el uso de los conceptos de la visión y de aprendizaje de manera descriptiva y apoyada en la metodología de sistemas blandos, un abordaje interpretativo de la teoría de sistemas. Antes, sin embargo, la necesidad de este tipo de enfoque es justificada, el potencial de contribución de los conceptos de la visión y del aprendizaje es descrito y el enfoque en sí es caracterizado. Los recursos explotados para la construcción del trabajo son, principalmente, la literatura disponible, variados ejemplos, argumentación y descripción. Las contribuciones del artículo incluyen una perspectiva diferenciada de comprensión de la gestión estratégica de MYPEs, más conocimiento sobre algunos aspectos poco abordados en estudios anteriores, así como la indicación de temas y enfoques potencialmente útiles para futuras investigaciones.

Palabras-clave: Aprendizaje; Visión compartida; Conversación estratégica; Gestión estratégica; Visión. 


\section{INTRODUÇÃO}

Oganizações predominantes, com mais de $90 \%$ das empresas no Brasil e nas economias em geral, as micro e pequenas empresas (MPEs) têm grande relevância. Elas promovem o desenvolvimento socioeconômico com a geração de empregos e inovações, além de serem fundamentais para a revitalização econômica pós-crise, por nascerem em grande número e se multiplicarem rapidamente (Acs, Carlsson e Karlsson, 1999; Najberg, Puga e Oliveira, 2000). Como ocorre normalmente com as organizações dos mais variados tipos, também para as MPEs, a gestão estratégica é crítica na definição do nível de contribuição gerada por elas para a sociedade, por determinar, em boa parte, a condição de sobrevivência e o desempenho das empresas.

Não por acaso, países líderes no estudo e no incentivo ao desenvolvimento dessas empresas, como o Reino Unido, têm programas de apoio especificamente visando a gestão estratégica delas. Realizada pelos proprietários-dirigentes nas MPEs, a gestão estratégica promove a compatibilidade da condição dessas empresas com o ambiente externo, a busca de vantagens competitivas, a formação de estratégias e o desenvolvimento da visão. Esta consiste na imagem mental de um futuro desejado a realizar, que oferece aos membros das MPEs, a começar pelos dirigentes, a principal orientação estratégica que motiva e direciona seus esforços presentes na construção de um futuro desejado para os negócios (Allali, 2003; Avenier, 1996; Bayad e Garand, 1998; Cossette, 2003; Mintzberg, Ahlstrand e Lampel, 2010; Moreau, 2004; Varraut, 1999). O compartilhamento da visão também promove a formação da cultura organizacional baseada nos valores dos proprietáriosdirigentes, dando à coletividade das pessoas que compõem as MPEs traços do jeito de ser, do que fazem e do que querem fazer aqueles encarregados pela gestão estratégica (Filion e Lima, 2011).

A visão é central na gestão estratégica das MPEs por definir muito dos seus fundamentos. De acordo com a descrição da escola empreendedora em estratégia feita por Mintzberg, Ahlstrand e Lampel (2010), a visão é a base do pensamento estratégico nelas e faz com que as estratégias sejam predominantemente deliberadas. Segundo os autores, isso ocorre já que, nessas organizações, a visão define os elementos principais das estratégias e da gestão estratégica, que são complementadas em seus detalhes pelas estratégias emergentes. A compreensão do conceito de visão é fundamental para se entender a gestão estratégica das micro, pequenas e médias empresas (Allali, 2003; Avenier, 1996; Bayad e Garand, 1998; Cossette, 2003; Filion, 1988, 1993, 2004; Lima, 2004, 2007, 2010a; Mintzberg, Ahlstrand e Lampel, 2010; Moreau, 2004; Varraut, 1999) e também o empreendedorismo (Filion, 1988, 1993, 2004; Filion e Lima, 2009, 2010). O caráter fundamental da visão nas MPEs deriva do fato de que, nelas, a gestão estratégica é alicerçada no 
Edmilson de Oliveira Lima, Louis Jacques Filion, Oscar Dalfovo \& Vladas Urbanavicius Junior

modo de pensar e nas atividades dos proprietários-dirigentes, refletindo as idiossincrasias destes, que, normalmente, contam com a participação de muito poucos ou nenhum outro membro da organização na administração e na direção. Adicionalmente, o processo estratégico é pouco elaborado nas MPEs no que se refere ao uso de técnicas administrativas e métodos analíticos (Mazzarol e Reboud, 2009). Isso faz com que sejam essenciais na gestão estratégica das MPEs aspectos intimamente conectados à visão, tais como a aprendizagem, a compreensão das coisas, as aspirações, o discernimento e a intuição dos proprietários-dirigentes. Portanto, a visão apresenta-se como um determinante importante dos resultados da gestão estratégica para a condição de sobrevivência e o desempenho das MPEs, tendo consequentemente um impacto relevante sobre as contribuições delas para a sociedade. Nesse sentido, merece atenção na pesquisa acadêmica e na prática da Administração.

Apesar de os estudos sobre a visão nas MPEs já terem obtido certo avanço (Allali, 2003; Bayad e Garand, 1998; Carrière, 1989, 1990; Cossette, 1996, 2003; D’Amboise e Nkongolo, 1992; Filion, 1988, 2004; Lima, 2000, 2004, 2007; Mintzberg, 1996; Nkongolo, D’Amboise e Garnier, 1994; Revolon e Delecroix, 1998; Verstraete, 1997; Varraut, 1999), permanece carente de compreensão o processo em que ela se faz compartilhar pelos membros em geral dessas organizações. Afinal, para chegar a governar o esforço da coletividade desses membros com vistas à construção do futuro desejado pela direção, a visão precisa ser compartilhada. Assim, o ensaio aqui apresentado tem por objetivo explicitar características da gestão estratégica das MPEs e de seus estudos não muito discutidas na literatura e gerar contribuições para se compreender como a visão faz-se compartilhar nessas organizações, não apenas por seus dirigentes. Para atingirmos tal objetivo, lançamos mão da literatura disponível, de exemplos e de nossa capacidade argumentativa, tudo sem deixarmos de considerar o conceito de aprendizagem. Segundo estudos teóricos e empíricos precedentes, o conceito mostra-se particularmente relevante para o compartilhamento da visão e a gestão estratégica das MPEs.

\section{A RELAÇÃO DIALÓGICA ENTRE A VISÃO E A APRENDIZAGEM}

A visão é uma imagem mental, projetada no futuro pelos dirigentes, do espaço que querem ver eventualmente ocupado por seus produtos, assim como a imagem mental do tipo de organização de que precisam para chegar a isso (Filion 1988, 2004). Pode-se identificar uma relação dialógica entre visão e aprendizagem na literatura. De um lado, um dado grupo de autores trata a 
visão como um constructo que motiva a obtenção de novos conhecimentos e habilidades pelos atores-chave nas organizações (Filion, 1999; Hamel e Prahalad, 1989, 1993, 1994a, 1994b; Redding e Catalanello, 1994; Senge, 1990). Evidentemente, para esses autores, a visão não apenas motiva a aprendizagem, mas principalmente a ação estratégica que transforma a realidade organizacional conduzindo-a no sentido do futuro desejado, indicado pela própria visão - e tal ação, em si, normalmente também é uma fonte de aprendizagem (Argyris e Schön, 1974, 1978; Kim, 1993a, 1993b; Kolb, 1984; Schön, 1983). O papel da visão como motivadora da aprendizagem pode ser ilustrado por uma passagem do estudo de Lidtka e Rosenblum (1996):

[A]chieving significant change is about disrupting alignment and opening gaps-cognitive gaps in the minds of change recipients between current reality and some future vision. This is the logic behind Hamel and Prahalad's view of the articulation of strategic intent as the catalyst of the strategy-making processes. Also, the creative tension caused by the desire to close the gap is what drives learning. This argues for a new set of questions that seek to open new gaps, as well as close old ones. Closing the gap, correcting the lack of alignment, is necessary for increasing stability and efficiency and fostering high performance. (p. 144; negrito nosso).

A aprendizagem, por outro lado, é um processo que dá sustentação e, ao mesmo tempo, dinamiza a evolução contínua da visão, que é um constructo subjetivo e sistêmico (Filion, 1988, 1996b, 1996c). A visão constitui um constructo subjetivo que evolui ao menos em parte pela aprendizagem dos atores estratégicos (Carrière 1989, 1990 ; Filion 1990, 1991a, 1991b ; Robbins e Duncan, 1988). Com os trabalhos desses diferentes autores, pode-se observar que a aprendizagem e a evolução da visão são dois processos que se moldam mutuamente, um contribuindo para o desenvolvimento do outro. Portanto, o conceito de aprendizagem é importante e útil para a compreensão da formação da visão nas MPEs. Essa perspectiva converge com o destaque dado por Dodgson (1993) e Leavy (1998) ao caráter promissor do conceito de aprendizagem para os estudos da gestão estratégica. O conceito é atraente principalmente por (1) seu amplo valor analítico, que repercute no número ascendente de campos de estudo que dele tiram proveito; (2) seu caráter dinâmico, cuja exploração na construção de teorias enfatiza a condição de continuidade das mudanças organizacionais; (3) sua qualidade de integrador, por combinar os níveis de análise individual, organizacional e interorganizacional na pesquisa (Dodgson, 1993). Leavy (1998, p. 62) explica que tais características fazem da aprendizagem um conceito atraente em estratégia:

...in the strategy area, because the field of strategic management is itself inherently
interdisciplinary (Meyer, 1991; Rumelt et al., 1991; Prahalad and Hamel, 1994), and is
concerned with multiple levels of analysis, from the individual and organization right
through to the industry and international economy. The dynamic nature of learning, with its
emphasis on change and continual renewal, is particularly apt in today's new economy, in 
Edmilson de Oliveira Lima, Louis Jacques Filion, Oscar Dalfovo \& Vladas Urbanavicius Junior

which strategies must be continually developed in conditions of transition and nonequilibrium at industry level, where the static notions of strategy as decision making, positioning and fit are becoming less useful and appealing (Stalk et al., 1992; Hamel and Prahalad, 1993).

\section{A NECESSIDADE DE UMA ABORDAGEM SISTÊMICA DE INTEGRAÇÃO EM ESTRATÉGIA}

Contribuindo para a corrente de pensamento que enfatiza a centralidade dos dirigentes nos processos administrativos, o que concorda com a preponderância dos proprietários-dirigentes na administração das MPEs, Barnard (1938) foi um dos primeiros autores a considerar as atividades deles como sendo de natureza sistêmica e determinada, entre outros aspectos, por critérios não estritamente racionais de tomada de decisão. Quanto menos racionais, mais intuitivas as decisões tendem a ser. Uma decisão intuitiva é aquela cujo processo escapa à capacidade de explicação do tomador de decisão, apesar de ele confiar na correção de sua intuição e normalmente basear a decisão em suas habilidades e experiências (Simon, 1989). O dirigente não está sempre em condições ótimas para tomar decisões baseadas em análises racionais; ele depende, portanto, de seu julgamento e de sua intuição para resolver situações-problema que demandam respostas imediatas (Barnard, 1938).

Esse tipo de situação-problema exige que os dirigentes não se atenham aos métodos intelectuais, às técnicas de discriminação de fatores e à esfera da ação logicamente determinada. $\mathrm{O}$ processo de organização lhes exige perceber a organização em seu conjunto e considerar o contexto geral pertinente, além de reconhecer seu próprio papel no todo em questão. Os elementos centrais implícitos nessa dinâmica são o sentimento, o julgamento, a percepção, a proporção, o equilíbrio e o senso do que é apropriado; "it is a matter of art rather than science, and is aesthetic rather than logical”, diz Barnard (1968, p. 235).

Calori (1998) destaca que essa perspectiva foi, por muito tempo, marginalizada devido à ortodoxia racionalista em estratégia que prevaleceu até o ano de 1994, quando o papel da intuição criativa começou a ser fortemente reconhecido graças ao grande sucesso dos livros The Rise and Fall of Strategic Planning (Mintzberg, 1994) e Competing for the Future (Hamel e Prahalad, 1994a). Ambos os livros criticaram as abordagens tradicionais sobre como realizar e compreender a gestão estratégica.

A atenção à definição precisa do que significa o pensamento estratégico na prática é fortemente limitada devido à popularidade do conceito e à frequência de sua utilização - 
comumente os estudos descrevem apenas o que o conceito não é: o tradicional planejamento estratégico (Liedtka, 1997, 1998). A partir dessa constatação, esta mesma autora descreve cinco atributos do pensamento estratégico que considera como os principais na prática:

- Perspectiva sistêmica: o pensamento estratégico é baseado em uma perspectiva sistêmica; o dirigente possui um modelo mental do sistema completo de criação de valor, de sua organização e de seu papel nesse sistema, além de compreender as interdependências que nele ocorrem.

- Atenção à intenção: o pensamento estratégico é dirigido à visão (também chamada de intenção estratégica por Collins e Porras (1994) e Hamel e Prahalad (1989)). É a visão que permite aos dirigentes ter senso de direção na realização das atividades de sua organização e no desenvolvimento da organização em si, de modo a evitar distrações e a dar convergência às diferentes ações estratégicas ao longo do tempo. Essa energia psíquica é rara e, frequentemente, marca a diferença entre o sucesso e o fracasso das empresas, sustenta Liedtka $(1997,1998)$.

- Pensamento ao longo do tempo: os dirigentes relacionam passado, presente e futuro. O pensamento estratégico, além de ser apontado para o futuro pela visão, marca a discrepância entre a condição presente e a condição futura desejada como fator crítico que molda a ação presente. O passado serve como fonte inspiradora para as previsões e como repertório a ser explorado em iniciativas de solução dos problemas presentes e futuros. Uma comparação contínua se faz na oscilação iterativa entre ponderações à luz do passado, do presente e do futuro. Portanto, o pensamento estratégico, oscilando quanto ao tempo, utiliza a memória organizacional (e também a memória individual de um ou mais indivíduos) e o contexto histórico institucional para a criação do futuro.

- $\quad$ Formulação de hipóteses: o pensamento estratégico se nutre também da geração de hipóteses e ele as testa à medida que avança. Trata-se do seu processo central. Desse modo, ele evita a dicotomia analítico-intuitiva característica da perspectiva tradicional e racionalista em estratégia. Ele é criativo e crítico em sua própria natureza, incluindo um processo cíclico iterativo de geração e de teste de hipóteses que produz possibilidades de solução - hipóteses emergem com a pergunta criadora "o que aconteceria se..." e são testadas com a pergunta crítica "se... então...?". 
Edmilson de Oliveira Lima, Louis Jacques Filion, Oscar Dalfovo \& Vladas Urbanavicius Junior

- Oportunismo inteligente: na prática, o pensamento estratégico é inteligentemente oportunista, de modo a impulsionar a realização de estratégias intencionais, mas sem tornar impossível a emergência de novas estratégias.

Essa descrição do processo estratégico feita por Liedtka $(1997,1998)$, assim como a do processo de gestão de Barnard (1938), não se refere especificamente às MPEs, mas pode também se aplicar a esse tipo de empresa. Nem um autor nem outro excluem essa possibilidade. O que descreve Liedtka $(1997,1998)$ pode ser entendido, segundo a perspectiva da teoria de sistemas, como um processo de aprendizagem dos atores estratégicos (os dirigentes) das empresas. Tal processo de aprendizagem ocorre, de acordo com o que dizem os dois autores, segundo um comportamento administrativo de natureza sistêmica dos responsáveis pela gestão estratégica.

A gestão estratégica promove a coerência da condição das MPEs com seu ambiente externo evolutivo e dinâmico por meio da aprendizagem (Wyer e Mason, 1998). Esses autores enfatizam a necessidade de se estudar o modo como os dirigentes dos pequenos negócios aprendem e dão condições a sua organização de se manter eficiente e evoluindo de acordo com as mudanças de seu ambiente externo. Adicionalmente, é necessário que uma perspectiva de pesquisa como essa, baseada no conceito de aprendizagem, possa integrar adequadamente a natureza sistêmica das atividades e do pensamento dos dirigentes. A perspectiva tradicional da estratégia, que inclui as abordagens do planning, do design e do posicionamento, trata das dimensões racionais e lógicas da gestão estratégica (Lima, 2010a). Contudo, ela não dá conta da globalidade dos aspectos desse processo, principalmente no caso das MPEs, organizações em que a gestão estratégica compreende muito de intuição, improvisação e outros aspectos que fogem à racionalidade estrita.

Assim, uma abordagem sistêmica de estudo é desejável, uma abordagem que leve em conta os diferentes aspectos humanos quanto ao pensamento e à ação na gestão estratégica, não apenas aqueles que sejam estritamente racionais. Seguindo o princípio da variedade requerida, uma abordagem deve ter a natureza adequada à problemática à qual se quer aplicá-la (Pauchant, 1997). Se, em todo caso, o comportamento administrativo dos dirigentes estudados não se apresentar como sendo de natureza sistêmica em um estudo empírico, a abordagem sistêmica ainda assim estará em condição de gerar compreensão sobre ele. 


\section{BASES DO COMPARTILHAMENTO DA VISÃO, SEGUNDO A ABORDAGEM DA APRENDIZAGEM SISTÊMICA}

Os indivíduos podem aprender recebendo elementos de aprendizagem provenientes de outros, além de poderem aprender por si sós. O campo de aprendizagem que se forma com as relações viabilizadoras da aprendizagem mútua contribui, portanto, para a aprendizagem promovida pela gestão estratégica conduzida pelos dirigentes (Lima, 2005, 2008). Nesse processo, as relações entre pessoas e a comunicação são centrais para a difusão de elementos de aprendizagem entre os membros inseridos no campo (Lundberg, 1995). Nesse sentido, a rede de relação de cada membro é um importante meio de difusão da aprendizagem que propicia o compartilhamento da visão. Em situações de gestão estratégica envolvendo membros de uma única MPE, os proprietários-dirigentes buscam propagar elementos como inovações, novas ideias e a visão de acordo com seus interesses ligados à condução dos negócios. Isso implica que o processo de compartilhamento da visão não ocorre apenas de modo informal e livre, mas, em parte, de modo gerenciado. Se elementos da visão são compartilhados incluindo distorções que provocam desvios do comportamento que se espera para a realização da visão, os dirigentes e/ou outros membros tendem a empreender ajustes. Iniciativas de correção como essas estão no centro do processo de aprendizagem organizacional. Esta pode ser definida como a resultante de respostas dadas por membros às mudanças dos meios interno e/ou externo de sua organização com vistas a ajustar as ações e/ou a lógica de ação em vigor para corrigir diferenças reais ou previstas (erros) entre os resultados de suas atividades e o desempenho que desejam obter (Argyris e Schön, 1978).

A partir dessas ideias, podem-se entender as MPEs como campos de aprendizagem e de difusão de conhecimento segundo o modelo da Figura 1A, proposto por Lima (2001, 2002). 
Edmilson de Oliveira Lima, Louis Jacques Filion, Oscar Dalfovo \& Vladas Urbanavicius Junior

Figura 1 - Relações entre níveis sistêmicos e conversa estratégica

A- Modelo das relações entre níveis sistêmicos nas pequenas organizações

B- Modelo da conversa estratégica de equipe de direção

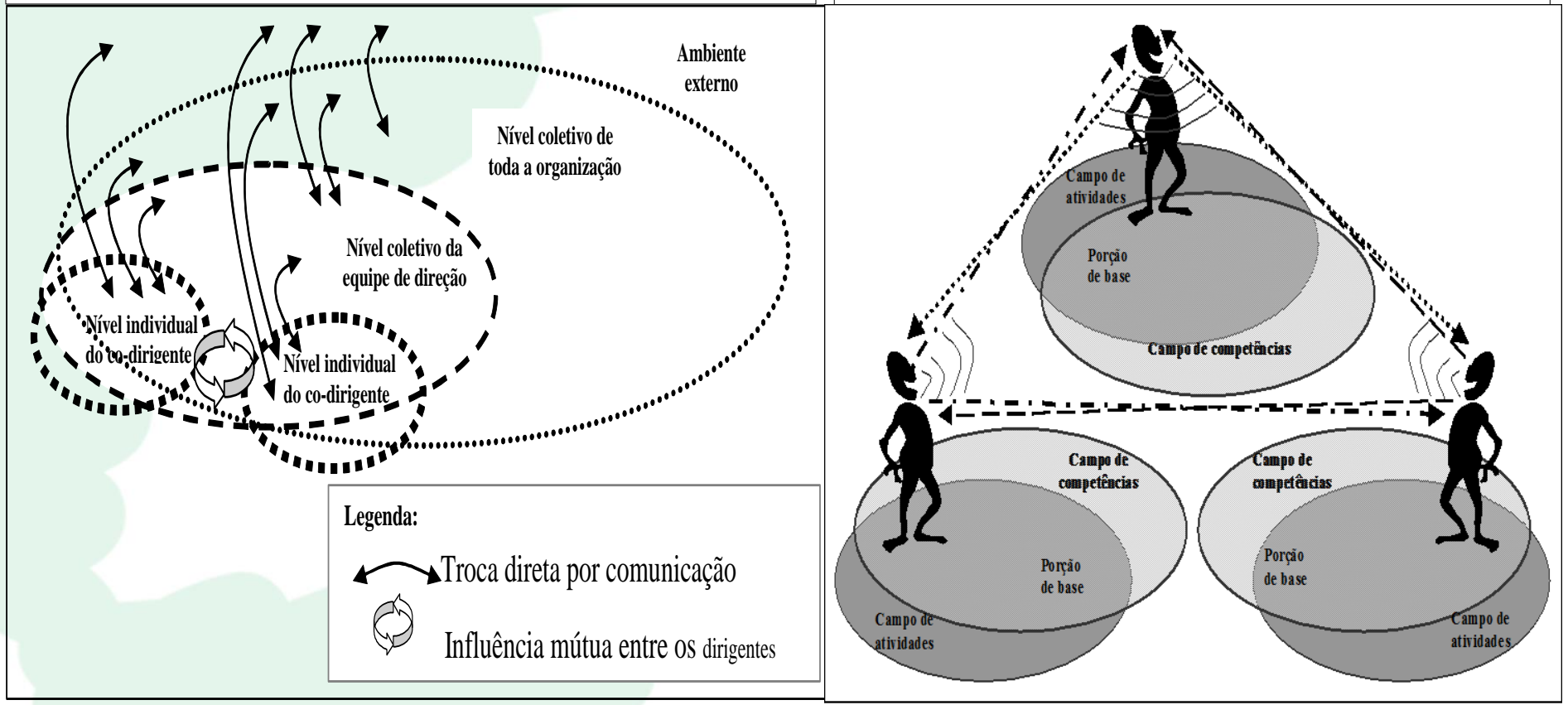

Fontes: Adaptado de Lima (2001, 2002, 2004).

Em consonância com a necessidade de uma abordagem sistêmica de integração, como exposto na seção precedente, Lima (2008) propôs a abordagem da aprendizagem sistêmica para os estudos em estratégia integrando o modelo da Figura 1A. A abordagem tem como características básicas o uso dos conceitos de visão e de aprendizagem de modo descritivo e apoiado na vertente interpretativa da teoria de sistemas que é a metodologia de sistemas flexíveis (Checkland, 1981). Ela mostra-se particularmente útil para a geração de conhecimentos sobre o modo de ocorrência da gestão estratégica nas micro, pequenas e médias empresas. Foi desenvolvida exatamente com esse propósito (Lima, 2008).

O modelo da Figura 1A, das relações entre níveis sistêmicos nas pequenas organizações (Lima, 2001, 2002), foi corroborado por pesquisas empíricas (Lima 2004, Lima e Zoschke, 2007) e aplicado de modo proveitoso em estudos mais recentes (Campos e Lima, 2011; Lima, 2009). Ele auxilia a caracterizar as dinâmicas de tais relações (entre os dirigentes, a equipe de direção, se houver uma, o conjunto dos membros da organização e o contexto desta). Adicionalmente, evidencia a realidade de que os dirigentes são atores preponderantes na administração das pequenas organizações e na definição de características organizacionais e do comportamento das pessoas nessas organizações. A forma do modelo expressa de modo visual a difusão das influências 
marcantes dos dirigentes no sistema organizacional, as quais definem em grande parte o modo de ocorrência e o conteúdo dos processos de aprendizagem e de difusão de elementos de subjetividade (visão, ideias e outros). Estes últimos determinam o compartilhamento da visão e estabelecem as bases da gestão estratégica nas MPEs. O modelo é útil para se entender a formação, a evolução e o compartilhamento da visão, assim como a gestão estratégica das pequenas organizações, processos que se constroem em grande parte pela aprendizagem e pelas relações entre os membros da organização e com pessoas externas a ela (Lima, 2008). As relações com o ambiente externo representadas no modelo incluem as relações com pessoas de outras organizações.

O modelo da Figura 1A apresenta interações diretas dos níveis sistêmicos, representadas pelas flechas, e indiretas, mediadas por algum nível. Por exemplo, na obtenção de informações críticas pelos dirigentes com os empregados da posição hierárquica mais inferior para a tomada de decisões estratégicas, o nível sistêmico individual dos dirigentes interage e aprende diretamente e indiretamente com o nível da coletividade de toda organização. No modelo, o fato de os níveis sistêmicos tanto dos dirigentes quanto da equipe de direção não estarem completamente inseridos na representação do nível coletivo de toda a organização reflete a realidade, pois nem todas as dimensões da vida dos membros da organização são internas a esta. Por seu turno, a influência mútua entre os dirigentes representada no modelo destaca o fato de que cada dirigente é um dos principais stakeholders do pensamento do outro e dos demais membros da organização (Mitroff, 1983) no que diz respeito ao que se faz em geral para a organização.

Outros resultados de pesquisa (Lima, 2004, 2007) inserem-se também na abordagem da aprendizagem sistêmica (Lima, 2008). Estudando a gestão estratégica realizada por equipes de direção em micro, pequenas e médias empresas, Lima (2004) identificou com sua revisão de literatura e com uma pesquisa empírica de profundidade o caráter central da visão. Os resultados da pesquisa apresentam a conversa estratégica, em associação à aprendizagem, como um dos principais processos viabilizadores da gestão estratégica nas pequenas organizações por ela ser essencial, entre outras coisas, para o desenvolvimento da visão compartilhada entre dirigentes. Ela torna possível o compartilhamento de elementos da subjetividade nas relações entre as pessoas referentes a questões estratégicas, de modo que a visão compartilhada, por exemplo, possa se formar e evoluir. Tais pessoas podem ser dirigentes, demais membros da MPE e pessoas externas às MPEs, como clientes, fornecedores e apoiadores, entre outros (Urbanavicius, 2013).

As conversas são essenciais para a realização dos processos de administração e podem ser uma base proveitosa para a aprendizagem (Mengis e Eppler, 2008). A conversa estratégica, mais especificamente, é o nascedouro da estratégia em uma organização (Von Krogh e Roos, 1995). Ela 
Edmilson de Oliveira Lima, Louis Jacques Filion, Oscar Dalfovo \& Vladas Urbanavicius Junior

é a manifestação de relações entre duas ou mais pessoas com a qual uma comunica à outra opiniões, ideias, visão ou outros elementos no que diz respeito a questões estratégicas de uma dada organização (Lima, 2004, 2007, 2009). Ela é orientada para o desenvolvimento da organização e a criação de seu futuro e ocorre pelas interações interpessoais para tratar de temas não-operacionais, tais como a criação e a aquisição de recursos para o futuro e como estes serão utilizados (Von Krogh e Roos, 1995).

A Figura 1B representa a conversa estratégica com o exemplo de uma equipe de direção de três dirigentes - mas as considerações feitas com o uso desse exemplo podem ser úteis para outras situações de gestão estratégica. O campo de atividades de um membro em uma organização é o campo de trabalho que a ele foi atribuído pela diretoria, acompanhado das consequentes expectativas quanto ao papel que ele deverá desempenhar. Nesse sentido, por exemplo, espera-se que o membro incumbido de dirigir as atividades de marketing ocupe-se das relações com os clientes, mas não de problemas de gestão da produção. Por sua vez, o campo de competências agrupa os elementos que conferem a um membro o poder de transformação de sua realidade segundo sua vontade e/ou seus projetos - elementos associados a suas capacidades, habilidades, conhecimentos e vivência (que inclui suas experiências), sua formação, sua história familiar e sua capacidade de aprendizagem. As pessoas, normalmente, desenvolvem um campo de competências pelo aprendizado ao longo de sua existência.

Cada participante contribui para o processo de conversa estratégica baseado, sobretudo, na porção do seu campo de competência que sustenta mais diretamente seu campo de atividade (Lima, 2004, 2007, 2009). Na Figura 1B, essa porção é chamada de porção de base. As pessoas, mais frequentemente, participam da conversa estratégica gerando contribuições a partir de seu conhecimento e de sua experiência (Urbanavicius, 2013). Essas idéias nos remetem à necessidade de complementaridade entre as porções de base dos participantes de modo que cubram suficientemente as necessidades de atividade da organização em questão e possam gerar uma visão compartilhada, ou outros aspectos relativos à gestão estratégica, com potencial de êxito (Lima, 2004, 2007).

\section{O COMPARTILHAMENTO DA VISÃO}

Um desafio relevante e com o qual se confronta a direção das MPEs é o de dirigir com harmonia as atividades de uma coletividade frequentemente heterogênea. Para vencer tal desafio dando à empresa a perspectiva de avançar rumo à realização das ambições da direção, compartilhar 
a visão com os membros da empresa em geral mostra-se algo crítico. Tal compartilhamento facilitará a coordenação, a gestão e a tomada de decisão. Permitirá canalizar os esforços para uma direção compreendida pelos colaboradores e dar foco e direcionamento à gestão do desenvolvimento da empresa. Segue um exemplo na figura 2, que ilustra essas ideias.

Figura 2- O caso Microvet

Ao longo dos primeiros anos, após sua fundação na cidade de Viçosa - MG em 1989, a empresa Microvet manteve-se na condição de microempresa. Suas atividades principais consistem em pesquisa, produção e comercialização de vacinas autógenas de prevenção a doenças suínas provocadas por bactérias.

Anteriormente, durante alguns anos, o casal fundador realizou suas atividades empresariais nas instalações da Universidade Federal de Viçosa (UFV), onde José Lúcio, o marido, já fazia pesquisas e lecionava em Medicina Veterinária havia mais de dez anos. Maria, sua esposa, desenvolvia com ele, ao longo de numerosos momentos de conversa estratégica, uma visão compartilhada com a qual privilegiavam a criação de uma microempresa. Ela dedicou progressivamente mais tempo para ajudar seu marido na produção de vacinas na universidade, pois os recursos do negócio eram muito restritos, assim como o pessoal e a disponibilidade de instrumentos e de instalações.

Essas atividades geravam ganhos tanto para a universidade quanto para o casal empreendedor. Contudo, à medida que as vendas aumentavam, o casal foi se dando conta das limitações para o crescimento dos negócios impostas pelas possibilidades reduzidas de operação na universidade. Por exemplo, a empresa chegou ao ponto em que precisava produzir nos fins de semana, mas a universidade não tinha pessoal para trabalhar nos laboratórios aos sábados e domingos.

O número de clientes desejosos de melhor atendimento aumentava. O casal continuava a trabalhar e a avançar. Atingiu enfim um nível elevado de desenvolvimento de uma visão para criar, por spin-off, sua própria empresa com independência da universidade. A visão estava clara e, ao mesmo tempo, bem articulada tanto em relação aos componentes externos (dimensões da oportunidade a explorar, forças a enfrentar no mercado, clientes a servir, fornecedores com os quais contar, sistema logístico necessário) quanto aos componentes internos (localização da empresa, configuração das instalações, modo de fabricação dos produtos, estrutura de trabalho, tipos de empregado a contratar).

Os dois sentiam uma grande necessidade de independência, precisavam ter uma empresa situada próximo à universidade, que explorasse a mesma rede logística e de fornecedores e requeresse investimento mínimo e um modo de funcionar econômico. Realizaram então o spin-off no início de 1989. O compartilhamento da visão com os empregados já havia começado antes mesmo de sua contratação pela discussão com eles sobre a maneira como a empresa deveria ser estruturada e funcionar. A reação dos candidatos à explicação dos elementos de visão constituiu um dos critérios de seleção e contratação. 
Edmilson de Oliveira Lima, Louis Jacques Filion, Oscar Dalfovo \& Vladas Urbanavicius Junior

Particularmente quanto ao pessoal de laboratório, o compartilhamento era facilitado pela paixão por medicina veterinária e microbiologia que os contratados tinham em comum com José Lúcio. Isso era natural, pois a contratação se fazia quase exclusivamente entre estudantes de mestrado e de doutorado da UFV. Eram, na maioria, estudantes que queriam aprender a profissão trabalhando ao lado de José Lúcio. O diálogo contínuo com o pessoal, impulsionado pelo interesse comum dos contratados com a direção em relação ao desenvolvimento de produtos e novas tecnologias, constituiu a base da articulação, do enriquecimento e da renovação da visão na Microvet.

A busca da evolução gradual nos negócios (um passo de cada vez) sempre foi uma característica da visão compartilhada e do estilo de direção de Maria e José Lúcio. Além disso, os dois se completam bem, trabalham e evoluem com harmonia nos negócios. Ao longo dos primeiros anos, José Lúcio esteve encarregado do desenvolvimento dos produtos, das análises de laboratório e da geração de inovações. Maria assumiu o papel de mulher de negócios, como responsável pelas demais atividades da empresa, inclusive a gestão de pessoal, bem modesta naquele momento, pois a empresa tinha apenas uma secretária e um assistente.

Desde o momento de preparação para a fundação, a visão compartilhada não parou de ser renovada pelos codirigentes ao longo das interações entre eles mesmos e também com os empregados e outras pessoas de sua rede de relação - como ilustra a Figura 4 mais adiante. A concepção, o desenvolvimento, a realização e a evolução de sua visão resultam de um processo contínuo de comunicação e de aprendizagem.

Em 1999, dez anos após a fundação, a empresa gerou uma contribuição de nível mundial ao inovar com o lançamento da vacina de prevenção da meningo-encefalite suína provocada por Streptococcus suis. O desenvolvimento da visão compartilhada associado à ênfase na qualidade da gestão e da comunicação na rede de relação, fora e dentro da organização, podem, com um passo de cada vez, fazer de uma microempresa criada com simplicidade uma líder mundial em sua área de atuação.

Fonte: Adaptado de Lima (2004) e Filion e Lima (2011)

A partir do estudo do caso Microvet e de outros de micro, pequenas e médias empresas de variadas áreas de atuação, pudemos identificar quatro práticas que facilitam o compartilhamento da visão. Elas estão relacionadas na figura 3. Por já estarem explicitadas e se mostrarem quase óbvias na leitura do caso Microvet, os elementos do quadro só são brevemente comentados aqui. O nível de qualidade e de realismo da visão a compartilhar com a coletividade dos membros da MPE influenciará a receptividade, a aceitação e o engajamento que tal visão receberá deles. Eles se mostrarão mais motivados a compartilhar e contribuir para aperfeiçoar uma visão se perceberem os dirigentes como pessoas experientes, que têm domínio do campo de atividade. Se os dirigentes respeitam o gradualismo e não se deixam levar por ideias demasiadamente ambiciosas ou irrealistas, 
a relação de compartilhamento será facilitada. A motivação daqueles chamados a compartilhar a visão tenderá a ser mais elevada. Há aí uma questão de segurança, de se poder confiar mais facilmente em pessoas bem preparadas e que sabem aonde vão. O potencial de compartilhamento e de geração de engajamento dessas pessoas será maior se elas nutrirem a mesma paixão que os dirigentes pelas atividades ou ideias em questão. Nesse sentido, um dirigente poderá beneficiar mais sua empresa se selecionar cuidadosamente o pessoal para contratar, preferencialmente, os candidatos que têm tal paixão e que poderão mantê-la compartilhada no trabalho. Ao mesmo tempo, cuidado faz-se necessário para que as pessoas com essa paixão não sejam do tipo que tem muita dificuldade para compartilhá-la e do tipo que tende a se tornar concorrente.

Figura 3- Práticas facilitadoras do compartilhamento da visão

\begin{tabular}{|c|c|}
\hline PRÁTICAS & EFEITOS SOBRE O COMPARTILHAMENTO \\
\hline $\begin{array}{l}\text { 1. Ter domínio da área de atuação e experiência } \\
\text { nessa mesma área }\end{array}$ & $\begin{array}{l}\text { Legitimidade do dirigente } \\
\text { Confiança recíproca } \\
\text { Delimitação de fronteiras (sobre o que fazer, quem } \\
\text { fazer...) mais facilmente aceitável por todos } \\
\text { Hierarquia incluindo respeito recíproco }\end{array}$ \\
\hline $\begin{array}{l}\text { 2. Contratação de pessoal com cultura } \\
\text { compatível com a dos dirigentes } \\
\text { Seleção de pessoal utilizando critérios } \\
\text { relacionados à visão }\end{array}$ & $\begin{array}{l}\text { Harmonia, convivialidade } \\
\text { Maior aprofundamento no processo de compartilha- } \\
\text { mento da visão } \\
\text { Mais motivação para aprender } \\
\text { Espectro de possibilidades mais delimitado para a } \\
\text { aprendizagem necessária }\end{array}$ \\
\hline $\begin{array}{l}\text { 3. Gradualismo, coerência, clareza na expressão } \\
\text { da visão }\end{array}$ & $\begin{array}{l}\text { Alvos mais precisos da visão } \\
\text { Atividades para realização da visão mais articuladas, } \\
\text { claras e lógicas } \\
\text { Maior possibilidade de reflexão, reavaliação e } \\
\text { aperfeiçoamento ao longo do tempo com } \\
\text { desenvolvimento da visão }\end{array}$ \\
\hline $\begin{array}{l}\text { 4. Transparência, frequência e intensidade da } \\
\text { comunicação a respeito da visão }\end{array}$ & $\begin{array}{l}\text { Enriquecimento do processo de desenvolvimento e de } \\
\text { realização da visão }\end{array}$ \\
\hline
\end{tabular}

Fonte: Adaptado de Filion e Lima (2011) 
Edmilson de Oliveira Lima, Louis Jacques Filion, Oscar Dalfovo \& Vladas Urbanavicius Junior

\section{COMPARTILHAMENTO E APERFEIÇOAMENTO DA VISÃO AO LONGO DO TEMPO COM A CONVERSA ESTRATÉGICA}

O caso Microvet apresenta a situação de uma empresa dirigida por uma equipe de direção composta por mais de um proprietário-dirigente. Nessa situação, antes de buscar compartilhar sua visão com os membros da organização em geral, é recomendável que os dirigentes estabeleçam uma visão compartilhada por eles mesmos. Sem isso, tendem a compartilhar visões ou elementos de visão individuais diferentes e até mesmo contraditórios. Isso poderia gerar confusão, falta de senso de direção entre os empregados e conflitos. Diferentemente, em uma MPE de um só proprietáriodirigente, o compartilhamento pode se fazer de modo mais simples entre este e os demais membros da organização, pois não há uma etapa anterior a cumprir, de formação de uma visão compartilhada na equipe de direção.

Segundo o que expomos nas seções anteriores deste artigo, a conversa estratégica é um processo essencial para o compartilhamento da visão. Para que esse compartilhamento ocorra, ela promove o compartilhamento de elementos de subjetividade entre as pessoas. Por exemplo, tais elementos podem ser a respeito das percepções que um ou mais dirigentes têm das tendências de desenvolvimento do setor de atividade de sua empresa ou, mais diretamente, sobre certos aspectos constituintes de uma visão potencial. Devemos acrescentar, contudo, que as interações requeridas para o compartilhamento da visão fazem com que adaptações e mudanças devam ser feitas em parte de seus elementos ao longo do processo para acomodar múltiplas perspectivas. Isso não é lamentável, já que as interações implicam frequentemente uma melhoria da visão, geralmente quanto a sua factibilidade e a sua realização.

Ao longo das interações, mesmo que se expresse a visão por escrito em um enunciado claro antes de compartilhá-la - o que é recomendável para se facilitar o compartilhamento -, certos elementos podem precisar de ajuste. Nesse momento, é necessário que a direção dê provas de paciência, de flexibilidade e de bom senso para escutar as sugestões e observar as reações dos demais membros da MPE e, em seguida, eventualmente integrar à visão compartilhada melhorias assim identificadas. Em situações que demandam rapidez, contudo, os dirigentes tendem a empregar modos mais diretivos para compartilhar a visão, o que é geralmente justificável e aceitável aos olhos dos membros.

A realidade das empresas nos mostra que o compartilhamento da visão não ocorre em um só episódio, mas em diferentes momentos ao longo do tempo. Ele deve constituir periodicamente o objeto de novos momentos de conversa estratégica; é o que produzirá a renovação da visão ao longo do tempo, além do seu compartilhamento. Se não for assim, a visão pode se tornar estática, perder 
em realismo, factibilidade, aceitabilidade e, enfim, ficar vazia de sua própria razão de ser. A empresa poderia estagnar. Os membros da organização realizariam tarefas que não fariam mais sentido por não se inserirem em um processo coerente cujo todo tenha uma progressão compreensível para cada um. Poder-se-ia dizer que, para um pedreiro, isso seria a diferença entre apenas posicionar pedras e construir uma catedral.

As condições que condicionam a evolução das numerosas MPEs demandam a renovação contínua da visão compartilhada por atividades de gestão estratégica baseadas na conversa estratégica e promotoras de aprendizagem. Enfatizando as características de complexidade e evolução contínua do ambiente externo das micro, pequenas e médias empresas, Wyer e Mason (1998) sustentam que é a gestão estratégica, por meio da aprendizagem, que mantém a compatibilidade da condição dessas empresas com seu meio externo. Tal concepção converge com o modelo de gestão estratégica como geradora de aprendizagem e renovação dessas empresas desenvolvido por Lima (2008) com base na realidade delas e com o uso da metodologia de sistemas flexíveis (Checkland, 1981). As mudanças do contexto assim como da situação das pessoas ligadas à empresa, além das chegadas e partidas de membros da organização, fazem com que seja necessário reconsiderar continuamente a visão compartilhada. As Figuras 4 e 5 apresentam, com suas duas grandes flechas, duas situações distintas de conversa estratégica que se renova ao longo do tempo: em uma MPE na qual a fonte principal da visão é uma equipe de direção e em outra em que ela é um único proprietário-dirigente. Nas duas situações, logicamente, a direção precisa ter estabelecido sua visão antes de buscar compartilhá-la com outras pessoas.

Figura 4- Com equipe de direção: compartilhamento e aperfeiçoamento da visão

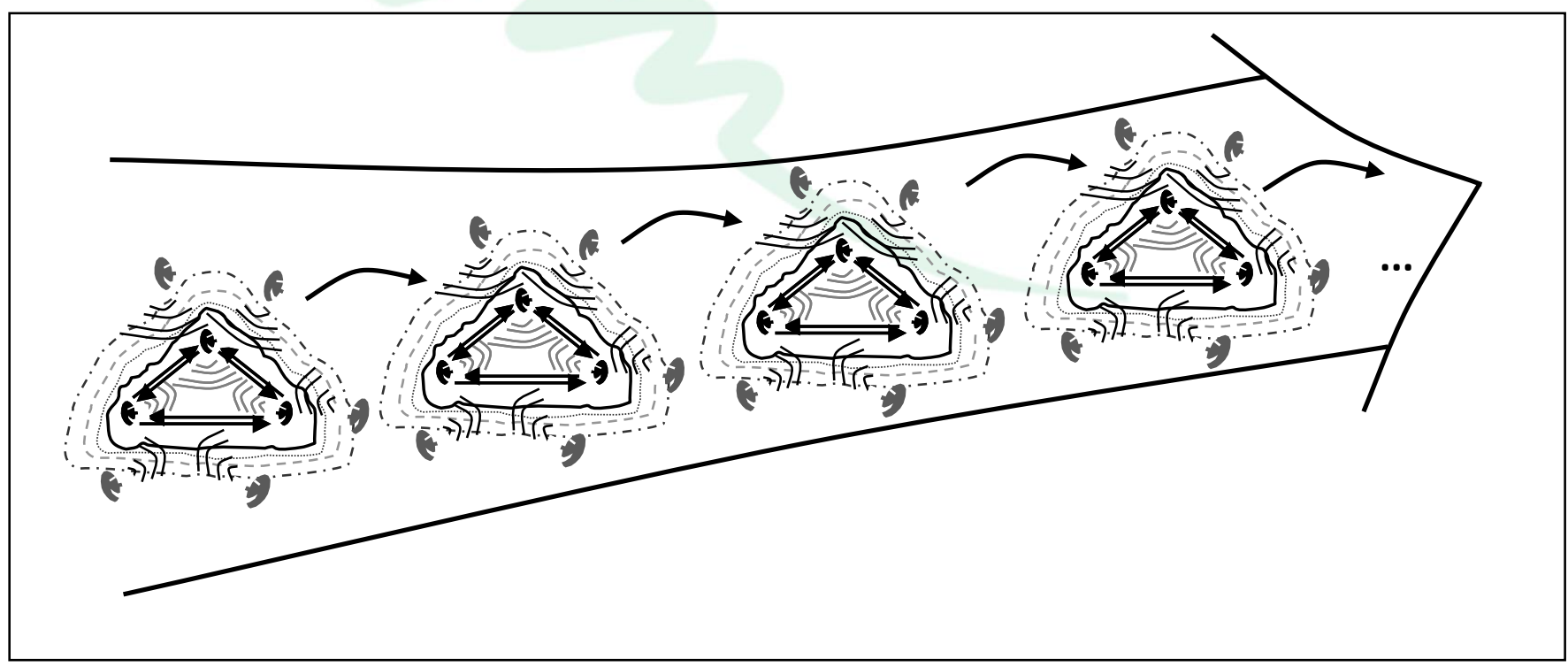

Fonte: Adaptado de Lima (2004) e Filion e Lima (2011) 
Edmilson de Oliveira Lima, Louis Jacques Filion, Oscar Dalfovo \& Vladas Urbanavicius Junior

De acordo com a Figura 4 (e relembrando a descrição da Figura 1B), quando do desenvolvimento da visão compartilhada no seio de uma equipe de direção, cada codirigente constitui a principal fonte de influências interpessoais um para o outro. Cada um é chamado a participar, principalmente considerando sua perspectiva a partir do seu campo de atividade, oferecendo contribuições a partir do seu campo de competência. Adicionalmente, eles têm muito a ganhar escutando outras pessoas, também de fora da equipe de direção, para receber outras contribuições e assim aumentarem a factibilidade e o potencial de êxito da visão. Contudo, como já dizíamos, sua tarefa, em um primeiro momento, precisa ser a de estabelecer uma visão compartilhada bem articulada no âmbito da direção. Depois disso, o compartilhamento pode ser feito com outras pessoas, sejam elas membros da empresa ou não.

Com pessoas de fora da empresa, é muito comum a situação de compartilhamento da visão com clientes ou clientes potenciais para convencê-los de que é um bom negócio comprar os produtos da empresa em questão e de que o futuro dela será favorável à continuidade dos bons negócios. Vê-se isso, por exemplo, com as novas empresas de informática que vendem sistemas computacionais complexos e caros. Devido ao alto índice de fracasso dessas empresas, elas normalmente são vistas como portadoras de grande risco de falta de continuidade do desenvolvimento e da assistência pós-venda para seu seus produtos. Contudo, um dos exemplos mais explícitos das ideias em questão é talvez a situação de um gerente de uma nova e pequena construtora tentando vender a um cliente potencial um apartamento na planta do primeiro empreendimento da empresa. Além de convencer o cliente em potencial sobre a idoneidade da empresa e de seus dirigentes e de que a obra será realmente realizada do início ao fim, o gerente precisa compartilhar com ele a visão da organização - previamente compartilhada pela direção com tal gerente e demais membros. Como se trata de uma nova empresa sem outros empreendimentos construídos ou em construção, grande parte da visão resume-se à planta apresentada ao cliente potencial e outras descrições de como será no futuro o empreendimento. Havendo o compartilhamento da visão e se o cliente potencial concluir que deve fazer a compra, grande parte da visão compartilhada será explicitada em um contrato de compra e venda. Este contrato descreverá as condições e os valores da transação assim como o imóvel em si, com inclusão da planta e de uma listagem dos tipos de material de construção que serão usados na obra. Com cada cliente potencial adicional, o processo se repetirá, se renovará e poderá ganhar novos contornos. Com a clientela, o compartilhamento da visão também evolui. 
Figura 5- Com um só proprietário-dirigente: compartilhamento e aperfeiçoamento da visão

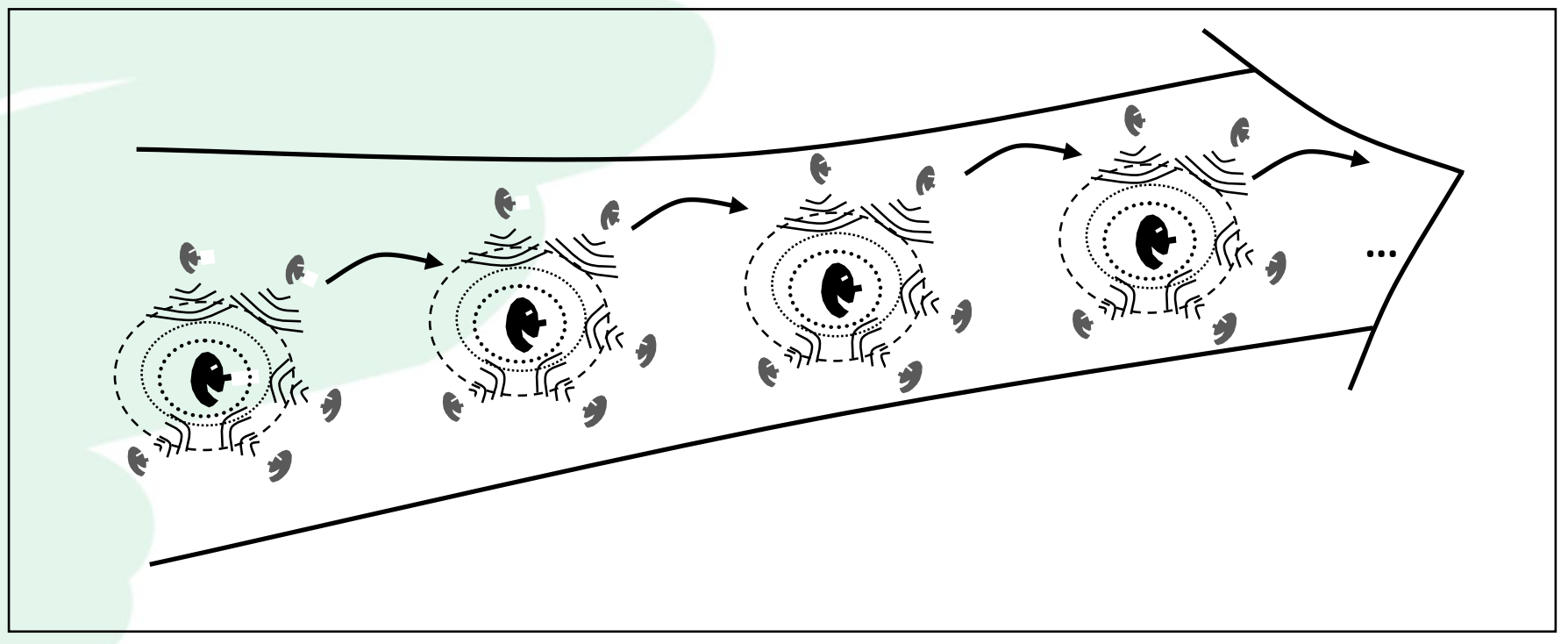

Fonte: Adaptado de Lima (2004) e Filion e Lima (2011)

O modelo da Figura 5 não compreende o processo, às vezes laborioso, de desenvolvimento da visão de uma equipe de direção. O fato de a realidade de uma empresa não incluir esse complicador é normalmente visto como positivo, já que o compartilhamento se mostra mais simples e com menos possibilidades de discordância e de conflito. Mas a situação da Figura 5 não oferece apenas vantagens. Ela compreende alguns inconvenientes. Um deles é de não poder contar com as interações intensas que a dinâmica de uma equipe de direção pode oferecer para melhorar a qualidade da visão. Claro, contudo, que o proprietário-dirigente único na direção poderia se beneficiar de trocas de ideia com pessoas de sua rede de relação, com um conselho de administração ou mesmo com um mentor ou coach. Mais adiante, quando os componentes principais de sua visão estiverem definidos, ele poderá tirar proveito também de trocas com seus empregados.

O exemplo da figura 6 a seguir, que contrasta com o caso Microvet, é útil para se compreender o desenvolvimento e o compartilhamento da visão orquestrados por um só proprietário-dirigente à frente de sua MPE. 
Figura 6- $\mathrm{O}$ caso Assados BomBoi ${ }^{2}$

Os brasileiros adoram a boa comida, principalmente quando se trata de carne. Muito ciente disso, além de ser um grande apreciador e bom preparador de carnes, Lucas abriu, no início dos anos 2000, seu restaurante para aproveitar a aprendizagem feita em um negócio anterior, em que, além de sócio, foi churrasqueiro.

Ele tem em mente uma visão cuja maioria dos componentes já tinha sido testada, mas que comporta novos elementos, como dirigir um restaurante na condição de único proprietário e usar um grande local alugado na lateral da estrada de seu bairro a cerca de 500 metros de seu restaurante anterior, comportando o dobro da área. Pela primeira vez, ele contrata mão de obra nesse tipo de atividade. Sua ideia é assim aproveitar ainda mais seu campo de competência com um novo conceito: servir costelas de boi assadas e de sabor diferenciado.

Sem ter que passar pelas dificuldades de entendimento com seu antigo sócio, Lucas se sente livre para dirigir os negócios como bem entende. Na cozinha, diante da churrasqueira, atrás do balcão ou no salão de atendimento nos momentos de interação com os clientes, ele trabalha sempre em proximidade com seus dois empregados, com quem a comunicação é intensa. Tal proximidade e tal intensidade de comunicação são chave para que não apenas receba contribuições de clientes e empregados para aperfeiçoar sua visão, mas também para que possa compartilhá-la sem a mediação e as dinâmicas por vezes complicadas de uma equipe de direção. Mesmo que os clientes, empregados e outras pessoas de sua rede de relação tenham contribuído para a evolução de sua visão de criação do negócio, sua churrascaria é dirigida segundo seus próprios valores e sua forma de ver como seu negócio pode se diferenciar no setor de atividade. Sem a moderação de seu antigo sócio, suas ambições acabam por impulsioná-lo a incorrer em muito mais risco e a observar menos o gradualismo do que em sua empresa anterior. A Assados BomBoi chega ao sucesso, mas seguindo uma progressão com momentos frequentemente caóticos e marcada por ciclos de altos e baixos que, por vezes, deixaram os empregados apreensivos.

Fonte: Adaptado de Filion e Lima (2011)

Seja na situação descrita pela Figura 1 ou pela Figura 4, os modelos representam, com o apoio dos exemplos, a evolução no tempo da visão que a direção compartilha na rede de relação interna e externa à MPE por meio de diferentes momentos de conversa estratégica. Independentemente da situação, o que se vê na realidade é que a visão evolui e se reconfigura de acordo com as mudanças do contexto e de outros aspectos relacionados à organização e a seus atores (como sugere um dos modelos de Lima (2008) e o trabalho de Lima (2007)), mas

${ }^{2} \mathrm{O}$ caso é real, mas, em sua descrição, o nome do restaurante e das pessoas é fictício. 
principalmente segundo as conversas estratégicas. Estas requerem espaço, tempo, atitudes e momentos apropriados para ocorrer com qualidade e servindo-se suficientemente da complementaridade dos campos de atividade e de competência daqueles que a empreendem.

Para fecharmos esta seção do texto, vamos um pouco mais adiante com a apresentação de exemplos, acrescentando aqui mais um, o da figura 7, que ilustra os efeitos positivos que pode propiciar não apenas o compartilhamento, mas também a participação dos membros da empresa em geral no processo visionário.

Figura 7 - Contribuições de costureiras em microempresas de confecção ${ }^{3}$

A cidade de Nova Friburgo - RJ tem uma grande concentração de empresas de confecção, principalmente de produção de lingerie. Em uma das lojas de varejo de roupa feminina da cidade, o sócio e dirigente chamado Fernando observa um comportamento peculiar de algumas clientes. Elas examinam com muita atenção todos os detalhes de novos produtos com design diferenciado que chegam do fornecedor à loja, sem, no entanto, comprá-los. Intrigado, ele acaba obtendo uma explicação interessante de sua sócia: essas mulheres, costureiras ou chefes de costura em microempresas, procuram novas ideias para produtos ou novos modos de produção para sugerir a seu patrão. É uma maneira de contribuírem para a renovação da visão na empresa em que trabalham. Se as ideias levadas interessarem ao patrão, as mulheres retornarão à loja a fim de comprar o produto, que, por sua vez, servirá de modelo para a produção de outros. O modelo será descosturado para que os detalhes de sua confecção sejam bem compreendidos e, a partir daí, conversas estratégicas poderão considerar a possibilidade de integração de novidades nas linhas de produto existentes e na renovação da visão nas microempresas. Fernando ficou sabendo que várias dessas contribuições ajudaram no sucesso de microempresas no entorno de sua loja. Na maioria dos casos, essas colaboradoras recebem uma recompensa por sua iniciativa aproveitada.

Fonte: Adaptado de Lima (2001, 2010b) e Filion e Lima (2011)

Essa anedota nos proporciona mais clareza sobre como os membros em geral das MPEs podem gerar ativamente contribuições para a concepção ou renovação de uma visão compartilhada, visão que deve apresentar certa flexibilidade apoiada na abertura de espírito da direção. O fato em si de essas costureiras tomarem esse tipo de iniciativa revela que elas já compartilham ao menos alguns elementos da visão da direção da empresa em que trabalham, pois conseguem imaginar,

\footnotetext{
${ }^{3} \mathrm{O}$ caso é real. Os nomes são fictícios.
} 
Edmilson de Oliveira Lima, Louis Jacques Filion, Oscar Dalfovo \& Vladas Urbanavicius Junior

mesmo que parcialmente, que tipo de inovação poderá interessar aos seus patrões e que efeitos suas sugestões poderão gerar para a empresa.

\section{CONSIDERAÇÕES FINAIS}

Este trabalho apresenta uma associação não usual de ideias e conceitos no campo da estratégia, com atenção centrada nas micro e pequenas empresas, organizações ainda carentes de estudos teóricos e empíricos nesse campo. Tal associação é promovida pela abordagem da aprendizagem sistêmica, que aqui é estendida com o detalhamento da compreensão do compartilhamento da visão com os membros das MPEs em geral e outros, como os clientes. Ademais, o uso de exemplos variados reforça a ancoragem empírica da abordagem. Nossa iniciativa de usar exemplificações teve dupla intenção: por um lado, a principal foi de facilitar o entendimento das ideias desenvolvidas e, por outro, ampará-las com elementos empíricos destacando sua coerência com a realidade da gestão estratégica das MPEs. Em nossa avaliação, a concretização dessas intenções explicita a validade e a utilidade da abordagem para se compreender a gestão estratégica das MPEs e melhorá-la, assim como para se buscar caminhos diferenciados e coerentes com as particularidades das MPEs na ampliação da pesquisa sobre o tema.

Um ponto ainda muito sensível nas MPEs quando se trata da aprendizagem organizacional e mesmo da aprendizagem em geral é a extrema dependência que essas organizações têm de seus dirigentes quanto à realização desses processos e à memória utilizada para manterem disponíveis informações, conhecimentos, habilidades e competências gerados. Pesam para tanto a tradicional preponderância do ou dos proprietários-dirigentes na MPE, o pequeno número de membros - em especial daqueles de competência bem desenvolvida - e a habitual tendência centralizadora da direção, muitas vezes atrelada à falta de preparo em administração e em empreendedorismo.

Gerar soluções para esse ponto sensível impõe-se como necessidade se a visão dos dirigentes inclui a aspiração à excelência e ao alto desempenho nos negócios. Contudo, como remediá-lo se a alta restrição de recursos - em especial de pessoal bem preparado e de recursos financeiros - limita sobremaneira as possibilidades de delegação? Mesmo que a MPE tenha algum grande talento entre os empregados, sejam eles gerentes ou não, tal ponto forte costuma ser transitório, dada a falta de expectativa de carreira e a margem apertada para ascensão salarial dos empregados nas pequenas organizações. Nessa situação, há um risco elevado de os dirigentes criarem uma grande dependência em relação aos frutos da aprendizagem retidos não por eles mesmos, mas por alguém que pode deixar a MPE a qualquer momento. É até mesmo possível que a 
pessoa venha a trabalhar para um concorrente ou que transforme-se ela mesma em um concorrente, criando sua empresa. O risco é considerável nas empresas de alta tecnologia, que investem muito no desenvolvimento de conhecimentos críticos e valiosos para seus negócios e para as quais costuma ser ainda mais difícil ter mais do que um (quando tem) empregado talentoso quanto a certas tecnologias.

Um caminho para se superar o desafio é o desenvolvimento de sistemas simples e não dispendiosos de informação e de gestão do conhecimento a serviço da gestão estratégica. Eles são mais atrativos à medida que os frutos da aprendizagem na MPE são mais valiosos aos olhos dos dirigentes e que tais sistemas lhes parecem menos complexos e caros. O tema já tem sido de interesse dos pesquisadores brasileiros há muitos anos. Isso se vê nos numerosos trabalhos feitos a seu respeito e apresentados anualmente na divisão de administração da informação no Enanpad (Encontro da Associação Nacional de Programas de Pós-Graduação em Administração) e no congresso feito regularmente por essa divisão no Brasil, o EnADI - Encontro de Administração da Informação. Há também outros trabalhos, em periódicos acadêmicos, como os de Dalfovo e Rodrigues (1998) e Rodrigues, Azambuja e Dalfovo (2005). Contudo, não se vê facilmente a aplicação dos resultados de estudos como esses nas MPEs para apoiar seus processos de aprendizagem em estratégia. É necessário avançar. Adicionalmente, continuam sendo necessários trabalhos geradores de contribuições aplicáveis na prática das MPEs segundo uma perspectiva sistêmica compatível com o conceito de visão, que leve em conta a simplicidade e a informalidade dos processos de gestão, assim como a intuição como recurso estratégico corrente nessas empresas.

Essas carências de contribuição para a prática, além do aprofundamento dos conhecimentos sobre o compartilhamento da visão e o papel da aprendizagem e da conversa estratégica, são temas promissores para futuras pesquisas. $\mathrm{O}$ tratamento destes, como já sinaliza a literatura, parece ter muito a ganhar com abordagens da estratégia que enfocam especialmente as relações entre as pessoas e suas microdinâmicas comunicativas. Segundo também o que sugere a literatura, tais temas e abordagens demandam principalmente o uso de métodos de pesquisa não muito correntes na pesquisa sobre as MPEs, como a pesquisa-ação e os estudos de inspiração etnográfica baseados na observação participante. 
Edmilson de Oliveira Lima, Louis Jacques Filion, Oscar Dalfovo \& Vladas Urbanavicius Junior

\section{REFERÊNCIAS}

Acs, Z. J., Carlsson, B., Karlsson, C. (1999). The linkages among entrepreneurship, SMEs and the macroeconomy. In: . (eds.). Entrepreneurship, small and medium-sized enterprises and macroeconomy. Cambridge: Cambridge University Press, p. 3-42.

Allali, B. (2003). Vision des dirigeants et internationalisation des PME marocaines et canadiennes du secteur agro-alimentaire. 333 f. Tese (Doutorado) - Écoles des Hautes Études Commerciales de Montréal, Montreal.

Argyris, C., Schön, D. (1974). Theory in Practice: Increasing Professional Effectiveness. San Francisco: Jossey-Bass.

Argyris, C., Schön, D. (1978). Organizational learning: a theory of action perspective. Reading: Addison Wesley.

Avenier, M.-J. (1996). La stratégie tâtonnante : des interactions récursives entre vision et action stratégique, Anais... Conférence de l'AIMS, Lille (França).

Barnard, C. I. (1938). The functions of the executive. Cambridge: Harvard University Press.

Bayad, M., Garand, D. J. (1998). Vision du propriétaire-dirigeant de PME et processus décisionnel: de l'image à l'action. Anais... Congrès International Francophone de la PME - CIFPME, Metz (França).

Campos, T. M., Lima, E. (2011). Aprendizagem e adequação das operações para realizar estratégias de exportação em micro e pequenas empresas. Revista Ibero-Americana de Estratégia - RIAE, 10(2), 159-180.

Carrière, J.-B. (1989). Strategic vision: an empirical study. Anais... Annual Conference of the International Council for Small Business (ICSB). Windsor (Canada).

Carrière, J.-B. (1990). La vision stratégique en contexte de PME : cadre théorique et étude empirique. Revue Internationale PME, 3(3-4), 301-325.

Checkland, P. (1981). System thinking, system practice. Chichester: Wiley.

Cossette, P. (1996). La vision stratégique du propriétaire-dirigeant de PME : étude de cartographie cognitive. Revue Internationale PME, 9(1), 123-142.

Cossette, P. (2003), Méthode systématique d'aide à la formulation de la vision stratégique : illustration auprès d'un propriétaire dirigeant, Revue de l'Entrepreneuriat, 2(1), 1-179. 
D’Amboise, G., Nkongolo, J.-M. (1992). Vision stratégique : concept et signification empirique. Caderno de pesquisa n. 92-109. Groupe de recherche sur la PME et l'entrepreneurship (GRPME), Faculté des Sciences de l'Administration, Université Laval.

Dalfovo, O., Rodrigues, L. C. (1998). Delineamento de um sistema de informação estratégico para tomada de decisão nas pequenas e médias empresas do setor têxtil de blumenau. Revista de Negócios, 3(3), 43-56.

Dodgson, M. (1993). Organizational learning: a review of some literature. Organization Studies, 14(3), 375-394.

Filion, L. J. (1988). The strategy of successful entrepreneurs in small business: vision, relationships and anticipatory learning. Tese de doutorado, University of Lancaster.

Filion, L. J. (1990). Vision and relations: elements for a entrepreneurial metamodel. Anais... Annual Babson Entrepreneurship Research Conference. In: CHURCHIL, N. C. et allii (eds.) Frontiers of Entrepreneurship Research. Wellesley: Center for Entrepreneurial Studies, 57-71.

Filion, L. J. (1991a). Vision and relations: elements for a entrepreneurial metamodel. International Small Business Journal, 9(2), 26-40.

Filion, L. J. (1991b). Vision et relations : clefs du succès de l'entrepreneur. Montreal : Les Éditions de l'Entrepreneur.

Filion, L. J. (1993). Visão e relações: elementos para um metamodelo empreendedor. RAE Revista de Administraçao de Empresas, 33(6), 50-61.

Filion, L. J. (1999). Espace de soi et vision. Caderno de pesquisa n. 99-01. Chaire d'entrepreneurship Maclean Hunter. Montréal: HEC Montreal.

Filion, L. J. (2004). Operators and visionaries: differences in the entrepreneurial and managerial systems of two types of entrepreneurs. International Journal of Entrepreneurship and Small Business, 1(1/2), 35-55.

Filion, L. J., Lima, E. (2009). As representações empreendedoras: um tema essencial, mas ainda negligenciado. Revista de Negócios, 14(2), 89-107. Disponível em http://proxy.furb.br/ojs/index.php/rn/article/view/1175/1130.

Filion, L. J., Lima, E. (2010). As representações empreendedoras: importantes temas para avançar em seu estudo. Revista de Negócios, 15(2), 32-52. Disponível em http://proxy.furb.br/ojs/index.php/rn/article/view/1195/1515.

Filion, L. J., Lima, E. (2011). Le partage de la vision dans les très petites entreprises. Entreprendre et innover, n. 9-10, 7-20. 
Edmilson de Oliveira Lima, Louis Jacques Filion, Oscar Dalfovo \& Vladas Urbanavicius Junior

Hamel, G., Prahalad, C. K. (1989). Strategic intent. Harvard Business Review, 67(3), 63-76.

Hamel, G., Prahalad, C. K. (1993). Strategy as stretch and leverage. Harvard Business Review, 71(2), 75-84.

Hamel, G., Prahalad, C. K. (1994a). Competing for the Future. Boston: Harvard Business School Press.

Hamel, G., Prahalad, C. K. (1994b). Strategic intent. International Review of Strategic Mangement, 4, 63-86.

Hoon, C. (2007). Committees as strategic practice: the role of strategic conversation in a public administration. Human Relations, 60(6), 921-952.

Kim, D. (1993a). A framework and methodology for linking lndividual and organizational learning: applications in TQM and product development. Tese de Ph.D., Massachusetts Institute of Technology.

Kim, D. (1993b). The link between individual learning and organisational learning. Sloan Management Review, 35(1), 37-50.

Kolb, D. (1984). Experiential learning: experience as the source of learning and development. Englewood Cliffs: Prentice-Hall.

Leavy, B. (1998). The concept of learning in the strategy field: review and outlook. Management Learning, 29(4), 447-466.

Liedtka, J. M. (1997). Everything i need to know about strategy i learned at the National Zoo. The Journal of Business Strategy, 18(1), 8-11.

Liedtka, J. M. (1998). Linking strategic thinking with strategic planning. Strategy and Leadership, 26(4), 30-35.

Liedtka, J. M., Rosenblum, J. W. (1996). Shaping conversations: making strategy, managing change. California Management Review, 39(1), 141-157.

Lima, E. (2000). Visão estratégica e padrões emergentes como complementares na pequena empresa. Revista de Negócios, 5(2), 1-10.

Lima, E. (2001). A formação em empreendedorismo face à realidade do pequeno empresário brasileiro: a partir de estudos de vanguarda, o que devemos enfatizar? Brasília: Sebrae Nacional. Texto de base da palestra de mesmo título feita em 30 set. 2001. Evento "Treinamento para Atualização da Equipe do EMPRETEC". Disponível em: http://www.inf.furb.br/ dalfovo/EdmilsonLima. 
Lima, E. (2002). La gestion stratégique de PME face au monde évolutif des affaires: une approche d'apprentissage systémique. Anais... Congrès International Francophone en Entrepreneuriat et PME - CIFEPME.

Lima, E. (2004). Équipe de direction, vision partagée et apprentissage dans le management stratégique de PME. Tese de Ph.D., HEC Montreal, Canadá. (Disponível também em www.inf.furb.br/ dalfovo/EdmilsonLima)

Lima, E. (2004). Équipe de direction, vision partagée et apprentissage dans le management stratégique de PME. Tese de Ph.D., HEC Montreal, Canadá. (Disponível também em www.inf.furb.br/ dalfovo/EdmilsonLima)

Lima, E. (2007). Visão compartilhada, equipe de direção e gestão estratégica de pequenas e médias empresas: um estudo multi-caso e internacional. Revista de Negócios, 12(4), 86-100.

Lima, E. (2008). A Gestão estratégica de pequenas e médias empresas segundo a abordagem da aprendizagem sistêmica. Gestão \& Planejamento, 9, 22-34.

Lima, E. (2009). Relações internas e conversa estratégica nas pequenas e médias empresas. Economia \& Gestão, 9(20), 73-88.

Lima, E. (2010). Estratégia de pequenas e médias empresas: uma revisão. REGE, 17(2), 169-187.

Lima, E., Zoschke, A. C. K. (2007). Relações dos dirigentes e gestão estratégica de pequenas e médias empresas. Revista de Administração e Inovação, 4, 150-164.

Lundberg, C. C. (1995). Learning in and by organizations: three conceptual issues. International Journal of Organizational Analysis, 3, 10-23.

Mazzarol, T., Reboud, S. (2009). The strategic management process. In: . The strategy of small firms - strategic management and innovation in the small firm. Cheltenham: Edward Elgar, 149-175.

Mengis, J., Eppler, M. (2008). Understanding and managing conversations from a knowledge perspective: an analysis of the roles and rules of face-to-face conversations in organizations. Organization Studies, 29(10), 1.287-1.313.

Mintzberg, H. (1994). The rise and fall of strategic planning. New York: Free Press.

Mintzberg, H. (1996). The entrepreneurial organization. In : Mintzberg, H., Quinn, J. B. (eds.). The Strategy Process: Concepts, Contexts, Cases. 3 ed. Upper Saddle River: Prentice-Hall, 614-623.

Mintzberg, H., Ahlstrand, B., Lampel, J. (2010). Safári de estratégia. 2 ed. São Paulo: Bookman. 
Edmilson de Oliveira Lima, Louis Jacques Filion, Oscar Dalfovo \& Vladas Urbanavicius Junior

Mitroff, I. (1983). Stakeholders of the organizational mind. San Francisco: Jossey Bass.

Moreau R., (2004). L’identité entrepreneuriale de soi. Revue Internationale PME, 17(2), 11-42.

Najberg, S., Puga, F. P., Oliveira, P. A. S. (2000). Criação e fechamento de firmas no Brasil: Dez. 1995/Dez. 1997. Textos para discussão, n. 79. Banco Nacional do Desenvolvimento Econômico e Social (BNDES). 39 p.

Nkongolo, J.-M., D’Amboise, G., Garnier, B. (1994). L'association entre la manifestation de la vision stratégique des propriétaires-dirigeants de PME et la performance de leur entreprise. Révue International PME, 7(1), 35-61.

Pauchant, T. (1997). La gestion des systèmes complexes - définition, nécessité et apprentissage. Montreal : HEC Montréal. Documento de estudo, não publicado.

Redding, J. C., Catalanello, R. F. (1994). Strategic readiness - the making of the learning organization. San Francisco: Jossey-Bass.

Revolon, F., Delecroix C. (1998). L'acuité stratégique de l'entrepreneur. Anais... Conférence Internationale de l'AIMS, Louvain-la-Neuve (Bélgica). Site internet visitado em 10 juillet 2000: http://www.essca.asso.fr/aims/actes98/papiers/REVOLON.pdf .

Robbins, S. R., Duncan, R. B. (1988). The role of the CEO and top management in the creation and implementation of strategic vision. In: Hambrick, D. C. (ed.). The executive effect: concepts and methods for studying top managers. London: Jai Press, 205-233.

Rodrigues, L. C., Azambuja, R. A., Dalfovo, O. (2005). Sistema de informação estratégico para pequena e média empresa. RAI - Revista de Administração e Inovação,2(2), 49-61.

Schön, D. (1983). The reflective practitioner: how professionals think in action. New York: Basic Books.

Schmitt, C., Lima, E., Husson, J. (2012). Apoyo para los emprendedores en la concepción de su visión. Gestão e Planejamento, 13(3), 848-865.

Senge, P. M. (1990). The fifth discipline: the art and practice of the learning organization. New York: Doubleday Currency.

Simon, H. A. (1986). What we know about the creative process. In: Kuhn, R. L. (ed.). Frontiers in Creative and Innovative Management. Cambridge: Ballinger Publishing Co., 3-21.

Simon, H. A. (1989). Making management decisions - the role of intuition and emotion. In : Agor, W. H. (ed.). Intuition in organizations: leading and managing productively. Newbury Park: Sage, 23-39. 
Urbanavicius, V. (2013). Conversa estratégica e equipes de direção de micro e pequenas empresas: as interações dos codirigentes com não codirigentes. Tese de doutorado. Programa de PósGraduação em Administração. Universidade Nove de Julho - UNINOVE. (Disponível também em: http://www.inf.furb.br/ dalfovo/EdmilsonLima/).

Varraut, N. (1998). Démarche stratégique du dirige ant-propriétaire de PME. Anais...Congrès International Francophone sur la PME - CIFPME, Nancy (França). Site internet visitado em 2 mai 1999 : http://www.airepme.univ-metz.fr/Comm/Varraut.pdf .

Varraut, N. (1999). De la vision à l'intention stratégique: une application au dirigeant propriétaire de PME. Economie et Société, série Sciences de Gestion, n. 26-27.

Verstraete, T. (1997). Socialisation entrepreneuriale et construction de la vision stratégique du créateur d'entreprise : un essai constructiviste. Anais... Colloque Constructivisme et Science de Gestion. Lille (France).

Von Krogh, G., Roos, J. (1995). Conversation management. European Management Journal, 13(4), 390-394.

Recebido: 19/01//2013

Aprovado: 27/03/2013 